\title{
Copper photoelectrodeposition onto boron doped diamond electrodes at different doping level to enhance nitrate electroreduction.
}

\author{
A. B. Couto, M. R. Baldan, N. G. Ferreira \\ Instituto Nacional de Pesquisas Espaciais (INPE), 12201-970, São José dos Campos - SP - \\ Brazil.
}

\begin{abstract}
Photoelectrodeposition of copper on boron-doped diamond films (BDD) was investigated. In this work, two different doped films were analyzed. Copper particles were deposited in the potentiostat mode and under UV irradiation. The BDD film as-grown and the BDD film modifed with $\mathrm{Cu}(\mathrm{Cu} / \mathrm{BDD})$ on the surface were characterized by Raman Spectroscopy and Scanning Electron Microscopy (SEM) respectivily. These electrodes were tested as electrocatalysts for nitrate reduction in Britton-Robinson buffer solution $(\mathrm{pH}=3)$. Electrochemical measurements showed that the electrode with high doping level displayed the best electrocatalytic activity.
\end{abstract}

\section{INTRODUCTION}

Nitrate electroreduction is one of the methods used to abatement of these ions from the polluted waters since it offers low cost operation. Besides, this technique is considered a clean process and highly effective [1]. The mechanism for the nitrate electroreduction is very complex and depends strongly on the experimental parameters such as the $\mathrm{pH}$, the supporting electrolyte and the choice of the electrode material [2-4]. In this sense, boron doped diamond (BDD) appears as an excellent electrode to study the nitrate reduction due to its outstanding electrochemical features such as the wide potential window in aqueous solutions and the weak adsorption for the most types of molecules $[5,6]$. It is noteworthy that is very important to reduce the overpotential for the nitrate reduction in aqueous media, since its reduction occurs near the water reduction. One way of achieving this is by modifying the electrode surface with catalytic materials. In particular, this can be achieved by depositing copper particle on the BDD surface, which exhibits the best electrocatalytic activity considering the kinetics for the nitrate reduction process [7]. Taking into account the BDD semiconducting characteristic, its photoactivity may be explored. So, the photo-assisted metal deposition method is very useful for the preparation of efficient electrode material [8]. The diamond in its natural state is considered a semiconductor with band gap energy of $5.5 \mathrm{eV}$. Due to its extremely wide band gap and the fact of the conduction band edge is located at a very negative potential (-4.0 V versus SHE (Standard Hydrogen Electrode)), the photogenerated electrons have extremely high reducing power [9]. So, the diamond serves as both a source of electrons for reduction of the ion to be deposited and as a substrate for deposition process. Thus, the aim of this work is to investigate the photoelectrodeposition of copper on semiconducting BDD films with different doping levels. Furthermore, these modified electrodes were applied to nitrate electroreduction, since the copper catalyses this process. 


\section{EXPERIMENTAL DETAILS}

The films were grown by hot filament-assisted chemical vapor deposition (HFCVD) technique using the gas mixture of $1 / 99 \%$ of the $\mathrm{CH}_{4} / \mathrm{H}_{2}$ with a pressure of 50 Torr and substrate temperature around $800^{\circ} \mathrm{C}$, during $16 \mathrm{~h}$. The films were deposited on the silicon substrate after seeding pre-treatment [10]. Boron source was obtained by an additional hydrogen line passing through a bubbler containing $\mathrm{B}_{2} \mathrm{O}_{3}$ dissolved in methanol with a controlled $\mathrm{B} / \mathrm{C}$ ratio that led to films with different doping level of $10^{19}$ and $10^{21}$ atoms.cm ${ }^{-3}$, denominated as electrode E1 and electrode E2 respectively.

Electrochemical measurements were made using the Autolab PGSTAT 302 equipment with a three-electrode cell. The geometric area of the diamond films in contact with the electrolyte was $0.13 \mathrm{~cm}^{2}$. A platinum mesh served as a counter electrode and $\mathrm{Ag} / \mathrm{AgCl} / \mathrm{KCl}_{\text {(sat) }}$ was used as the reference electrode. Prior to the photoelectrodeposition, the films were exposed under UV irradiation for $2 \mathrm{~h}$ to promote the oxygen functional groups that serves as anchor points for $\mathrm{Cu}$ deposited improving the interfacial adhesion between BDD films and the metal coating [13]. The photoelectrodeposition of $\mathrm{Cu}$ particles on diamond films was performed in the potentiostatic mode, at a fixed potential of $-0.6 \mathrm{~V}$ for a time of 10 min, in a $1 \mathrm{mmol} \mathrm{L}^{-1} \mathrm{CuSO}_{4}, 50 \mathrm{mmol} \mathrm{L}^{-1} \mathrm{H}_{2} \mathrm{SO}_{4}$ aqueous solution, under UV irradiation. The light source was a home made system, composed by a set of five commercial lamps (Philips TUV $30 \mathrm{~W} / \mathrm{G} 30 \mathrm{~T} 8$ ) placed in a closed box. The UV irradiation at the electrode position was $12 \mathrm{~W} / \mathrm{m}^{2}$ measured by a radiometer. Before $(30 \mathrm{~min})$ and during the photoelectrodeposition, the solution was purged with $\mathrm{N}_{2}$. The $\mathrm{Cu}$ modified diamond films morphology was verified from the scanning electron microscopy (SEM) images using a Jeol JSM-5310 microscope. Nitrate reduction experiments were monitored by the linear sweep voltammetry using $0.01 \mathrm{~mol} \mathrm{~L}^{-1} \mathrm{KNO}_{3}+0.001 \mathrm{~mol} \mathrm{~L}^{-1}$ Britton-Robinson (BR) buffer $(\mathrm{pH}=3)$.

\section{DISCUSSION}

\section{Characterization of BDD films - Raman Measurements}

Figure 1 shows the Raman's scattering spectra of the electrode E1 and the electrode E2. The characteristic Raman peak close to $1332 \mathrm{~cm}^{-1}$, which corresponds to the vibration of a diamond first-order phonon, confirmed the quality of these BDD films. The effect of boron doping is reflected in the spectral features. The peak of the diamond $\left(1332 \mathrm{~cm}^{-1}\right)$ shifted to lower energies due to tensions caused by boron incorporation in the diamond films. Besides, the diamond peak decreased in intensity due to the high B content in such films. In addition, there is the appearance of the two bands located at $500 \mathrm{~cm}^{-1}$ and $1220 \mathrm{~cm}^{-1}$. The band at 1220 $\mathrm{cm}^{-1}$ is attributed to the reticular distortion by boron insertion in the crystal structure of the diamond. The broad band at $\sim 1220 \mathrm{~cm}^{-1}$ feature increases with the $\mathrm{B}$ concentration increase. The band at around $500 \mathrm{~cm}^{-1}$ is assigned to the vibration modes of the boron pairs [11]. The boron concentration in the diamond films was estimated from the fitting of $500 \mathrm{~cm}^{-1}$ peak using a combination of Gaussian and Lorenzian lines [12]. The acceptor concentrations were evaluated around $10^{19}$ and $10^{21}$ boron atoms $\mathrm{cm}^{-3}$ for the electrode E1 and the electrode E2 
electrodes, respectively. The highest doping level of the electrode E2 is clearly observed in figure 1 where the band at $1220 \mathrm{~cm}^{-1}$ is higher than the diamond peak.

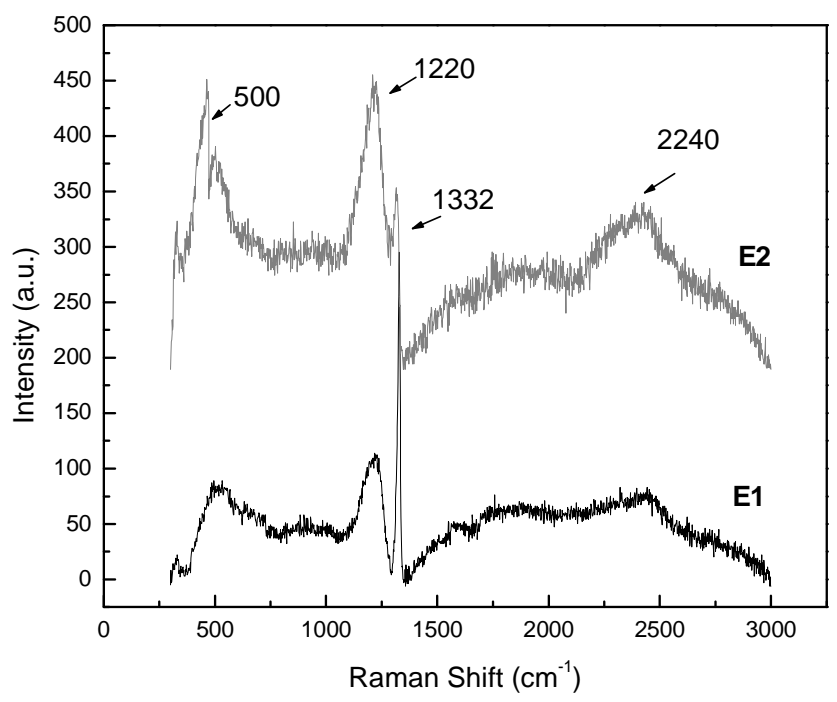

Figure 1. Raman spectra of E1 and E2 BDD electrodes.

\section{Copper particles photoelectrodeposition}

SEM analysis of the electrode E1 and the electrode E2 films after the $\mathrm{Cu}$

photoelectrodeposition are shown in figure 2 as images (a) and (b), respectively. The surface modification with $\mathrm{Cu}$ particles resulted in a morphology composed of rounded grains distributed throughout the surface of both films, with high density and uniformness of $\mathrm{Cu}$. These deposits may be explained due to the semiconductor character of such films. Firstly, the BDD surface presents high diamond purity where the conductivity is due to the boron excess at the top of its valence band. Therefore, the photoassisted process by UV irradiation generated additional electrons at the conduction band that could participate in the $\mathrm{Cu}$ electroreduction. In addition, the positive holes at the valence band may oxidize the water to molecular oxygen or hydroxyl radicals. Besides, the BDD is a semiconductor with a wide band gap. This process is improved due to this large band gap, where the recombination of the electrons is lower compared to that of conventional semiconductors [14]. In this way, this excess of electrons enhanced the $\mathrm{Cu}$ deposition. In a different way, previous work showed that for BDD electrode in the absence of UV irradiation, the copper deposit was obtained only at the diamond grain boundaries and/or in dispersed places of the grain faces [13]. 

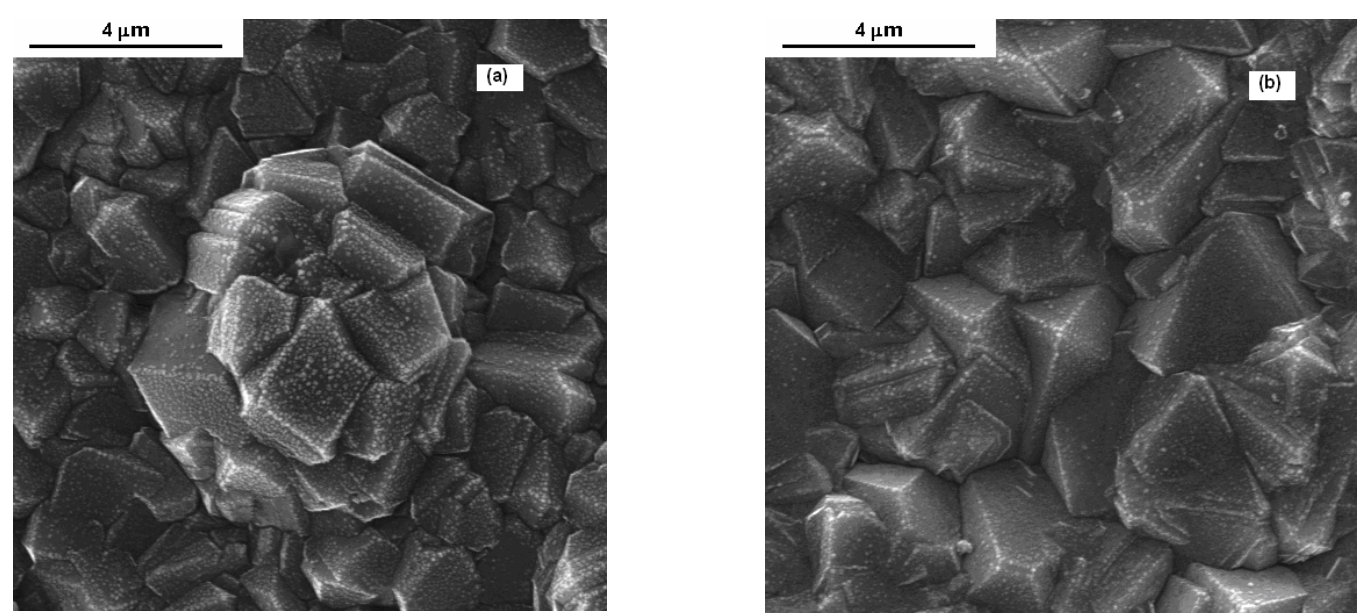

Figure 2. SEM images of E1 (a) and E2 (b) electrodes after $\mathrm{Cu}$ particle photoelectrodeposits.

\section{Nitrate Electroreduction}

These modified films were used to evaluate their performance in the nitrate reduction. Figure 3 presents linear sweep voltamograms in the presence of nitrate for as-grown and $\mathrm{Cu}$ /diamond films. For both electrodes, the cathodic currents for buffer BR are associated to the water reduction.
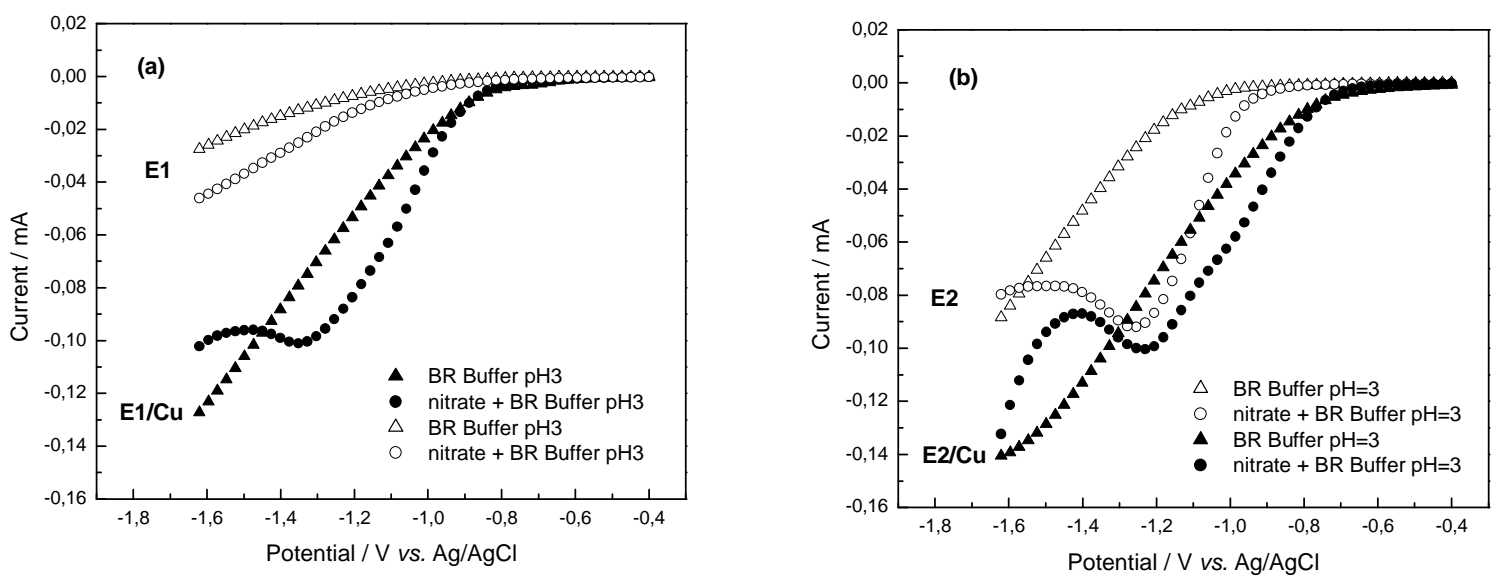

Figure 3- The response of diamond electrodes for $0.001 \mathrm{~mol} \mathrm{~L}^{-1}$ Britton Robinson buffer and for nitrate reduction in solution of $0.01 \mathrm{~mol} \mathrm{~L}^{-1} \mathrm{KNO}_{3}+0.001 \mathrm{~mol} \mathrm{~L}^{-1}$ Britton Robinson buffer. (a) E1 and E1/Cu; (b) E2 and E2/Cu electrodes.

From the above results, it is possible to observe that $\mathrm{Cu}$ deposited on diamond surface catalysed the electroreduction of nitrate for both electrodes. The nitrate electroreduction is a very complex process. Several products are possible depending on the experimental conditions such as the $\mathrm{pH}$ and the applied potential. In this work, only one cathodic peak is observed around $-1.25 \mathrm{~V}$ for $\mathrm{E} 1 / \mathrm{Cu}$ film, suggesting that nitrate reduction to ammonia is taking place at this potential. In Figure 2 (b), for $\mathrm{E} 2 / \mathrm{Cu}$, it is possible to observe the 
appearance of a slight new peak at around $-1.0 \mathrm{~V}$ associated to the nitrate reduction into hydroxylamine followed by the ammonia peak. This behavior may be explained by the highest conductivity of E2 electrode. These reduction processes were already observed by Aouina et al for the electroreduction of nitrate at a copper electrode in the neutral solution [15]. In addition, the stability of $\mathrm{Cu}$ particles on these films was evaluated from successive linear sweep voltammetry measurements for the nitrate reduction. The measurement reproducibility was obtained, indicating that the copper particles were consolidated on the electrode surface. This behavior can be explained by the $\mathrm{Cu}$ particle deposition on the diamond faces and the presence of oxygenated groups on the BDD surface induced by the $\mathrm{UV}$ pretreatment that serves as anchor point for $\mathrm{Cu}$ photoelectrodeposit.

\section{CONCLUSIONS}

This study showed that the copper photoelectrodeposition process on semiconducting diamond surface can be a good alternative for the preparation of modified electrode at different doping levels. By applying UV irradiation, the copper photoelectrodeposited presented high density and were uniformity distributed all over the crystal faces. This behavior was attributed to the generated additional electrons at the conduction band, where the recombination process on BDD is low and, consequently, ensured an increase in the density of copper deposits. Concerning the nitrate reduction process, the activity of $\mathrm{Cu}$ on the BDD was evident, where for $\mathrm{E} 1 / \mathrm{Cu}$ one cathodic peak was observed corresponding to ammonia peak while for E2/Cu electrode two cathodic peaks associated to the nitrate reduction were found. The first one refers to hydroxylamine and the second one to the ammonia peak. Besides, these electrodes showed reproducible measurements for nitrate reduction.

\section{ACKNOWLEDGMENTS}

The authors are very grateful to FAPESP (Process 2010/05391-0), CAPES and CNPq for the financial support.

\section{REFERENCES}

[1] M. Li, C. Feng, Z. Zhang, S. Yang, N. Sugiura, Bioresource Technology 101, 6553 (2010).

[2] T. Ohmori, M. S. El-Deab, M. Osawa, Journal of Electroanalytical Chemistry 470, 46 (1999).

[3] I. Katsounaros, G. Kyriacou, Electrochimica Acta 52, 6412 (2007).

[4] A. C. A. Vooys, R. A. van Santen, J. A. R. van Veen, Journal of molecular Catalysis A: Chemical 154, 203 (2000).

[5] A. N. Ndao, F. Zenia, A. Deneuville, M. Bernard, C. Lévy-Clément, Diamond and Related Materials 9, 1175 (2000).

[6] C. Lévy-Clément, N. A. Ndao, A. Katty, M. Bernard, A. Deneuville, C. Comninellis, A. Fujishima, Diamond and Related Materials 12, 606 (2003). 
[7] C. M. Welch, M. E. Hyde, C. E. Banks, R. G. Compton, Analytical Sciences 21, 1421 (2005).

[8] T. Wu, Y. Li, M. Chu, "Photoinduced Metal Deposition on Semiconductor Particles," Handbook of photochemistry and photobiology, American Scientific Publishers (2003) pp.249-280.

[9] P. Muret, C. Saby, Semicond. Sci. Technol. 19, 1 (2004).

[10] R. C. Mendes de Barros, E. J. Corat, N. G. Ferreira, T. M. Souza, V. J. Trava-Airoldi, N. F. Leite, K. Iha, Diamond Related Materials 5, 1323 (1996).

[11] P. W. May, W. J., Ludlow, M. Hannaway, P. J. Heard, J. A. Smith, K. N. Rosser, Diamond Related Materials 17, 105 (2008).

[12] M. Bernard, A. Deneuville, P. Muret, Diamond Related Materials 13, 282 (2004).

[13] A. B. Couto, L. C. D. Santos, J. T. Matsushima, M. R. Baldan, N. G. Ferreira, Applied Surface Science (2011) (in press).

[14] Y. L. Zhong, A. Midya, Z. Ng, Z. Chen, M. Daenen, M. Nesladek, K. P. Loh, J. Am. Chem. Soc. 130, 17218 (2008).

[15] N. Aouina, H. Cachet, C. Debiemme-Chouvy, T. T. M. Tran, Electrochimica Acta 55, 7341 (2010). 